NBER WORKING PAPER SERIES

CAN LEARNABILITY SAVE NEW-KEYNESIAN MODELS?

John H. Cochrane

Working Paper 15459

http://www.nber.org/papers/w15459

\author{
NATIONAL BUREAU OF ECONOMIC RESEARCH \\ 1050 Massachusetts Avenue \\ Cambridge, MA 02138 \\ October 2009
}

I thank Larry Christiano, George Evans, and Bennett McCallum for comments. The views expressed herein are those of the author(s) and do not necessarily reflect the views of the National Bureau of Economic Research.

NBER working papers are circulated for discussion and comment purposes. They have not been peerreviewed or been subject to the review by the NBER Board of Directors that accompanies official NBER publications.

(C) 2009 by John H. Cochrane. All rights reserved. Short sections of text, not to exceed two paragraphs, may be quoted without explicit permission provided that full credit, including $\odot$ notice, is given to the source. 
Can Learnability Save New-Keynesian Models?

John H. Cochrane

NBER Working Paper No. 15459

October 2009

JEL No. E0

\begin{abstract}
$\underline{\text { ABSTRACT }}$
Bennett McCallum (2009), applying Evans and Honkapohja's (2001) results, argues that "learnability" can save New-Keynesian models from their indeterminacies. He claims the unique bounded equilibrium is learnable, and the explosive equilibria are not. However, he assumes that agents can directly observe the monetary policy shock. Reversing this assumption, I find the opposite result: the bounded equilibrium is not learnable and the unbounded equilibria are learnable. More generally, I argue that a threat by the Fed to move to an "unlearnable" equilibrium for all but one value of inflation is a poor foundation for choosing the bounded equilibrium of a New-Keynesian model.
\end{abstract}

John H. Cochrane

Booth School of Business

University of Chicago

5807 S. Woodlawn

Chicago, IL 60637

and NBER

john.cochrane@gsb.uchicago.edu 


\section{Can Learnability Save New-Keynesian Models?}

Bennett McCallum (2009), extending a long literature, argues that "learnability" can save NewKeynesian models from their indeterminacies.

McCallum and I agree on the most important points. Standard New-Keynesian Taylor-Rule models have multiple, economically valid solutions. There is no reason in standard economics to pick only the unique locally-bounded solution. If you want to throw out the other solutions, you need to add some new principle. "Learnabilty" is, potentially, an extra principle that could do the trick.

However, I don't think "learnability" does, in fact, solve the problem, at least as expressed in this paper. First, I think McCallum went wrong in applying Evans and Honkapohja's (2001) results. He assumed that the monetary policy shock is directly observable. Agents need to observe it, not recover it by running regressions. Removing that assumption reverses the result: Under the Taylor Principle, the unique locally bounded equilibrium is, in fact, the only one that is not learnable. The explosive equilibria are learnable.

Second, even if the learnability results hold, I still don't think the result provides a satisfactory model of inflation determination. Is inflation really determined at a given value because for any other value the Fed threatens to take us to a valid but "unlearnable" equilibrium? Why should we care about such a threat?

\section{Model setup}

For space and clarity, I will concentrate entirely on the simple model, presented on McCallum's p. 4-5 with learnability results on p. 12, and I'll use McCallum's notation. To recap, the model consists of a "Fisher equation" coming from consumer's first order conditions,

$$
R_{t}=E_{t} \pi_{t+1}
$$

and a Taylor rule, expressing the central bank's behavior,

$$
\begin{aligned}
R_{t} & =\frac{1}{a} \pi_{t}+e_{t} \\
e_{t} & =\rho e_{t-1}+\varepsilon_{t} .
\end{aligned}
$$

(I leave out constants in both equations.) Eliminating the nominal interest rate $R_{t}$, the equilibrium condition is

$$
\pi_{t}=a E_{t} \pi_{t+1}+u_{t}
$$

where

$$
u_{t} \equiv-a e_{t} .
$$

Assume that $1 / a>1$, following the Taylor principle. The equilibria of this model are any inflation path that solves the difference equation

$$
\pi_{t+1}=\frac{1}{a} \pi_{t}+e_{t}+\delta_{t+1}
$$

where $\delta_{t+1}$ is any random variable with $E_{t} \delta_{t+1}=0$. This arbitrariness of $\delta$ indexes the multiplicity of equilibrium inflation paths. 
It's useful to rewrite the equilibrium condition as ${ }^{1}$

$$
\left(\pi_{t+1}-\psi u_{t+1}\right)=\frac{1}{a}\left(\pi_{t}-\psi u_{t}\right)+a \psi \varepsilon_{t+1}+\delta_{t+1}
$$

where

$$
\psi \equiv \frac{1}{1-\rho a} .
$$

Now it is easy to see that there is a "unique locally bounded" equilibrium,

$$
\pi_{t}=\psi u_{t}
$$

Equivalently, in this equilibrium the variable $\delta_{t}$ that indexes equilibria jumps around with the monetary policy shock as

$$
\delta_{t}=-a \psi \varepsilon_{t}
$$

Given a choice of equilibrium at date $t$, expected future inflation follows

$$
E_{t} \pi_{t+j}-\psi \rho^{j+1} u_{t}=\frac{1}{a^{j}}\left(\pi_{t}-\psi u_{t}\right)
$$

Thus, the equilibrium (5)-(6) is the only one not expected to explode (unique locally bounded). But, as we agree, nothing yet rules out nominal explosions.

McCallum: the locally bounded equilibrium is learnable

Now, suppose agents don't know $\psi$ and instead "estimate the relationship $\pi_{t}=\psi_{1 t} u_{t} . "\left(\psi_{1}\right.$ means estimated, $\psi_{1 t}$ means the estimated value at time $t$.)

The simplest "learnability" criterion is this: If you woke up in the equilibrium $\pi_{t}=\psi u_{t}$, and you didn't know $\psi$, could you (one individual) learn it from data on $\psi_{t}$ and $u_{t}$ ? In this case, there is no error term in the regression. You would know $\psi$ after one data point. I'll call this circumstance an "individually learnable" equilibrium, and that is certainly true here.

McCallum and Evans and Honkapohja study "convergence," a more subtle concept of learnability. Here, we suppose that nobody knows the parameter $\psi$, but they guess it and update. When nobody knows $\psi$, the economy will potentially be in a different equilibrium, and everybody might "learn" the wrong lessons, in such a way never to end up at the right equilibrium. The ability of an equilibrium to be individually learnable is (I think) necessary for convergence, but not sufficient.

$$
\begin{aligned}
\left(\pi_{t+1}-\psi u_{t+1}\right) & =\frac{1}{a}\left(\pi_{t}-\psi u_{t}\right)-\psi\left(u_{t+1}-\frac{1}{a} u_{t}\right)-\frac{1}{a} u_{t}+\delta_{t+1} \\
\left(\pi_{t+1}-\psi u_{t+1}\right) & =\frac{1}{a}\left(\pi_{t}-\psi u_{t}\right)-\psi u_{t+1}+(\psi-1) \frac{1}{a} u_{t}+\delta_{t+1} \\
\left(\pi_{t+1}-\psi u_{t+1}\right) & =\frac{1}{a}\left(\pi_{t}-\psi u_{t}\right)-\psi u_{t+1}+\left(\frac{1}{1-\rho a}-1\right) \frac{1}{a} u_{t}+\delta_{t+1} \\
\left(\pi_{t+1}-\psi u_{t+1}\right) & =\frac{1}{a}\left(\pi_{t}-\psi u_{t}\right)-\psi u_{t+1}+\psi \rho u_{t}+\delta_{t+1} \\
\left(\pi_{t+1}-\psi u_{t+1}\right) & =\frac{1}{a}\left(\pi_{t}-\psi u_{t}\right)+\psi a \varepsilon_{t+1}+\delta_{t+1}
\end{aligned}
$$


This example also converges, as follows. If people start with a guess $\psi_{1 t}$, and the Fed just follows the usual rule (1), then from (2), equilibrium inflation is

$$
\pi_{t}=a E_{t} \pi_{t+1}+u_{t}=a \psi_{1 t} \rho u_{t}+u_{t}=\left(1+\rho a \psi_{1 t}\right) u_{t}
$$

In addition, suppose people update slowly, waiting a period to form a new guess from the perfectlymeasured relation they just observed,

$$
\psi_{1 t+1}=1+\rho a \psi_{1 t}
$$

Iterating forward, this sequence of guesses leads to

$$
\lim _{t \rightarrow \infty} \psi_{1 t}=\psi
$$

Though there are smarter things people could do, which converge faster, this establishes that agents can learn with very simple rules.

(McCallum assumes that people run linear regressions. He establishes convergence with leastsquares learning by applying Evans and Honkapohja's results, i.e. "Clearly the learnability conditions analogous to (15a)-(15c) are that the $1 \times 1$ matrices $a, \rho$, and $a \rho$ all have eigenvalues with real parts less than 1." The result is the same, but can't be reproduced in the compact manner of this example.)

McCallum also claims that the non locally-bounded equilibria are not learnable in "analogous fashion." This is important, of course: if all equilibria are learnable, then learnability doesn't help us to narrow them down. Though I disagree with the result, there are more important issues to settle.

Observable shocks and the opposite result

There is a deeper problem with McCallum's approach: He assumes that $u_{t}$ is directly observable. To run a regression of $\pi_{t}$ on $u_{t}$, you need data on $u_{t} ! u_{t}=-e_{t} / a$ is the monetary policy shock. We don't usually think that agents can observe it directly.

Can't agents learn the monetary policy shock by running regressions, i.e. infer $e_{t}$ from observations of $R_{t}$ and $\pi_{t}$ and the policy rule

$$
R_{t}=\frac{1}{a} \pi_{t}+e_{t} ?
$$

Alas, no. To measure $e_{t}$ in this way, you need to know $a$. And agents can't learn $a$. If they try to run this as a regression, the fail because the right hand variable is perfectly correlated with the error term: The bounded-equilibrium value of $\pi_{t}$ is

$$
\pi_{t}=\psi u_{t}=-\frac{\psi}{a} e_{t}
$$

More generally, the observables in this model are $\left(R_{t}, \pi_{t}\right)$. Since $u_{t}$ follows an $\operatorname{AR}(1)$ and the bounded equilibrium is $\pi_{t}=\psi u_{t}$, the observables in the bounded equilibrium follow the laws of motion

$$
\begin{aligned}
\pi_{t} & =\rho \pi_{t-1}+v_{t} \\
R_{t} & =\rho \pi_{t},
\end{aligned}
$$


where $v_{t}$ is a regression error. This is what agents can see and learn. And the parameter a does not appear. a is not identified from the equilibrium dynamics of the bounded equilibrium. (This is the major point of Cochrane 2007.) There is absolutely no way for agents to learn $a$ even individually, and hence there is no way for them to measure $u_{t}$. Equation (10) shows that the regression of $R_{t}$ on $\pi_{t}$ measures $\rho$, not $1 / a$.

In sum, to run McCallum's "learnability" regression of $\pi_{t}$ on $u_{t}$, agents need to be given, "from introspection or divine revelation," direct observation of the monetary policy shock $e_{t}$ or prior knowledge of the parameter $a$. Without that assumption, I have the opposite result: the bounded equilibrium is not learnable.

As another way to see the point, suppose that the Fed follows a policy that violates the Taylor principle,

$$
R_{t}=\rho \pi_{t} ; \rho<1
$$

Now, the equilibrium dynamics are

$$
\pi_{t+1}=\rho \pi_{t}+\delta_{t+1}
$$

There are multiple bounded equilibria this time. But the equilibrium dynamics (9) and (10) are exactly the same as in this case. There is no way for an agent to learn whether he lives in the Taylor rule, unique bounded equilibrium world with $1 / a>1$ or in this multiple-equilibrium, indeterminate world, by running any regressions.

The converse result holds for the explosive solutions. These solutions follow equilibrium dynamics

$$
\pi_{t+1}=\frac{1}{a} \pi_{t}+e_{t}+\delta_{t+1}
$$

As before, $\pi_{t}$ and $e_{t}$ are potentially correlated, so an OLS regression of $\pi_{t+1}$ on $\pi_{t}$ is biased in a finite sample. However, now $\pi_{t}$ is an explosive process, while $e_{t}$ and $\delta_{t+1}$ are stationary. Thus, the regression coefficient of $\pi_{t+1}$ on $\pi_{t}$ converges to $1 / a$ ! The explosive solutions are individually learnable. I don't know if the explosive solutions converge, but neither I nor McCallum cares about this extra step - we don't want these anyway, though for different reasons.

In sum, once we remove the assumption that agents can see the monetary policy shock directly, I reverse McCallum's main claimed results: the bounded equilibrium is not learnable and the explosive equilibria are learnable (at least individually).

\section{A subtle trap}

Now, agents can learn the law of motion (9) of the bounded equilibrium and hence make correct forecasts $E_{t} \pi_{t+j}=\rho^{j} \pi_{t}$. It is easy to conclude that this equilibrium is therefore learnable, despite the fact that agents cannot learn $a$ or observe $u_{t}$.

This is a mistake. The whole point of this class of models is that knowledge of the boundedequilibrium dynamics is not enough. Agents must know that alternative equilibria will lead to explosions. Equivalently, they must know that only one value of inflation today $\pi_{t}$ is consistent with "anchored" long run expectations $\lim _{j \rightarrow \infty} E_{t} \pi_{t+j}$. They must know they are in the Taylor world with $1 / a>1$ not the observationally equivalent world with $1 / a=\rho<1$. If agents form expectations based on the equilibrium law of motion $E_{t} \pi_{t+j}=\rho^{j} \pi_{t}$ then any value of inflation today can be an equilibrium. Much of Woodford's (2003) Interest and Prices is dedicated to this point. So much new-Keynesian writing is devoted to communicating (by means other than regressions) the Fed's commitments to the Taylor rule that I don't think it's necessary to go on. 
I think more generally this is where McCallum's analysis goes wrong. When discussing learnability in general, on p. 7 , he sets up a system with endogenous variables $x$ and exogenous variables $z$, which follow

$$
\begin{aligned}
x_{t} & =A E_{t} x_{t+1}+C x_{t-1}+D z_{t} \\
z_{t} & =R z_{t-1}+\varepsilon_{t}
\end{aligned}
$$

(These are McCallum's equations (10) and (11).) He then considers "fundamental solutions of form

$$
x_{t}=\Omega x_{t-1}+\Gamma z_{t} .
$$

and he writes "for RE to prevail, agents need to have their expectations based on accurate quantitative knowledge of $\Omega$ and $\Gamma$, what the agents need to learn about is the system's [equilibrium] law of motion."

That's not enough in a New-Keynesian model. For the New Keynesian equilibrium to form and be locally unique, agents must know $A$ as well, and they cannot learn that from the bounded equilibrium of this model.

McCallum could really have helped us by showing how learning works, and how equilibria are formed, in the simple New-Keynesian model. As above, when agents forecast based on past values of endogenous variables, all the forward-looking components so vital to the bounded equilibrium of the New-Keynesian model vanish. All McCallum does is map into Evans and Honkapohja's general framework, but it's not clear that framework applies to this problem.

Even so, would it work?

Even if McCallum's learnability results (and those of related authors, such as Woodford (2003)) were correct, I don't think they would solve the fundamental problem of multiple equilibria in new-Keynesian models.

How does the Taylor rule work? The Fed, undergraduate textbooks, and everyone's op-eds say that it stabilizes the economy, introducing an eigenvalue less than one. If inflation rises, the Fed raises interest rates, and this lowers "demand," which lowers future inflation.

The standard New-Keynesian model logic, as presented here, works in the opposite way. The Taylor rule destabilizes the economy. If inflation rises, the Fed commits to raise future inflation, and leads us off to nominal explosions. Ruling out such explosions, inflation must be where the Fed wants it to be in the first place. Alas, as McCallum and I agree, the "ruling this out" part stood on shaky ground. Nothing in economics rules out such a hyperinflation, and words such as Woodford's (2003, p. 128) are hardly reassuring :

"The equilibrium ... is nonetheless locally unique, which may be enough to allow expectations to coordinate upon that equilibrium rather than on one of the others."

I think the non-learnability of the bounded solution puts it on shakier ground still - there is no way for agents to learn of the Fed's hyperinflationary threats from time-series. They would have to learn it from Fed pronouncements - and the Fed is pronouncing exactly the opposite. (Conversely, the learnability of the unbounded solutions is pretty obvious - if we observe a Fedinduced hyperinflation, you can learn the Fed's reaction speed pretty quickly.)

But suppose I'm wrong - suppose the bounded solution is learnable and the unbounded ones are not. McCallum is then saying that inflation is determinate at one particular value because 
the Fed, by explosive reaction, threatens for any other initial value to take us to an equilibrium that is "unlearnable." This does not sound like a threat that will strike fear in Wall Street's heart, and "coordinate expectations" on anything other than confusion. (Compare it, for example to the severe and explicit threats in Atkeson, Chari, and Kehoe (2009).) In the centuries-long search for the price-level anchor in a fiat-money economy, is the threat to take us to an "unlearnable" equilibrium for all but one initial value really the answer? . 


\section{References}

Atkeson, Andrew, V. V. Chari, and Patrick J. Kehoe, 2009, "Sophisticated Monetary Policies," Manuscript, Federal Reserve Bank of Minneapolis.

Cochrane, John H., 2007, "Identification with Taylor Rules: A Critical Review" Manuscript, University of Chicago.

Evans, George W., and Seppo Honkapohja, 2001, Learning and Expectations in Macroeconomics, Princeton: Princeton University Press.

McCallum, Bennett T., 2009, "Inflation Determination with Taylor Rules: Is the New-Keynesian Analysis Critically Flawed?" Manuscript, Carnegie Mellon University; Revision of NBER Working Paper 14534, Forthcoming Journal of Monetary Economics.

Woodford, Michael, 2003, Interest and Prices, Princeton: Princeton University Press 